\title{
FNAC and Cell-block Study of Thyroid Lesions
}

\author{
Raafat A. Hegazy ${ }^{1, *}$, Abdelmonem A. Hegazy² \\ ${ }^{1}$ Pathology Department, Faculty Of Medicine, Zagazig University, Egypt \\ ${ }^{2}$ Anatomy Department, Faculty Of Medicine, Zagazig University, Egypt \\ *Corresponding Author: rhegazy@zu.edu.eg
}

Copyright $(2013$ Horizon Research Publishing All rights reserved.

\begin{abstract}
Aim of the study: To highlight the importance of cell-block study in combination with FNAC in the diagnosis of different thyroid lesions. Patients and methods: This study was a retrospective study of 85 Egyptian patients with thyroid swellings, coming to cytopathology unit, faculty of medicine, Zagazig U:niversity. FNAC and cell-blocks were performed for each case. Cytological results of FNAC were compared to the cell-block histopathological picture. Results: FNAC findings were diagnosed as follows: $52(61 \%)$ as colloid goiter, $5(5.8 \%)$ as Hashimoto thyroiditis, $2(2.3 \%)$ as branchial cleft cyst, $1.0(1.1 \%)$ thyroglossal cyst, $5(5.8 \%)$ follicular neoplasm without atypia, $2(2.3 \%)$ as follicular neoplasm with atypia, $2(2.3 \%)$ as suspicious of malignancy, $10(11.7 \%)$ papillary thyroid carcinoma, and 1.0 $(1.1 \%)$ thyroid carcinoma of undefined category. Insufficient cases were 5 in number. The sensitivity of FNAC in comparison with histopathological results of cell-blocks was $91.6 \%$ and specificity was $97.2 \%$. Conclusion: It is advised to perform cell-block for each case of FNAC of thyroid lesions to decrease the pitfalls and to improve the diagnosis and management of thyroid lesions.
\end{abstract}

Keywords Thyroid, Cytology, Histopathology, Lesions

\section{Introduction}

Neck swelling is a common clinical presentation all over the world. It has been mentioned in the literature of ancient Egyptian medicine [1]. Egyptians looked for neck swelling as it adds a great beauty and grace to the female. However, this view has been greatly changed nowadays, as it mostly indicates a thyroid problem that carries significant morbidity and even mortality if it is not managed. Diffuse swelling of the neck might occur in cases of anaplastic carcinoma, as the tumor is diffuse and infiltrating [2].

Thyroid nodules represent a very common clinical problem and the differential diagnosis includes thyroid cancer [3]. Despite the clinically normal gland, thyroid nodules were detected in more than half of the population at histopathological examination [4]. These nodules might be discovered incidentally during ultrasonographic evaluation of the neck, for reasons not related to thyroid gland $[5,6]$. The reported prevalence of the palpable nodules was $4-7 \%$ of adult population. Only $5 \%$ of nodules are malignant and the vast majority is non-neoplastic lesions or benign neoplasms [7]. While palpation is clinically important method for thyroid examination, it can be insensitive and inaccurate depending on the skill of the physician [8]. In order to avoid misdiagnosis and hence unnecessary surgery in patients with benign thyroid nodules, it is essential distinguish between benign and malignant lesions. In this respect, there are many different techniques used for diagnosis of such conditions, including radionuclide scanning, high-resolution ultrasonography and FNAC. However, the FNAC is regarded as the single most accurate and cost-effective procedure [9]. Nevertheless, like any other tests, it has its limitations and diagnostic pitfalls. These limitations include false negative or positive results and a finding that is not obviously benign or malignant and falls into the indeterminate or suspicious group [10].

\section{Objectives}

The aim of the present study is to assess the values of FNAC in clarifying the thyroid structure and to highlight the importance of its association with cell-block technique in a trial to avoid FNAC diagnostic pitfalls.

\section{Patients and Materials}

A retrospective study was done for 85 diagnosed cases of thyroid swellings referred to cytology unit, pathology department, faculty of medicine Zagazig University, in the period between January 2007 and December 2010. The case notes were retrieved and information about the age, sex, ultrasound findings and cytological and histological diagnoses were reviewed. Thyroid swellings were aspirated using (23/24) gauge disposable needles and following the standard procedures [11]. The smears were prepared for histological study. Four slide smears were made for each case and immediately fixed in $95 \%$ ethyl alcohol for about 30 $\mathrm{min}$. Two of the 4 slides were stained with hematoxylin and eosin (Hx \& E) and others with Giemsa and Papanicolaou (Pap) stains. The remnants in the syringe were clotted, or 
centrifuged. Then, they were fixed in neutral buffered formalin for 12 hours and processed as small cell-blocks. Diagnosis of cytological smears was done according to standard criteria defined by various authors [12]. Then, the results were categorized into normal and insufficient for diagnosis, benign, atypical follicular lesion of undetermined significance, follicular neoplasm, suspicious for malignancy, and malignant sampling [11].Aspirates with insufficient cellularity or poor quality smear were considered "unsatisfactory". The case was considered insufficient if less than four groups of follicular cells could be seen in the smear and the cell-block was negative for follicular cells. Cases of normal or insufficient diagnosis were reevaluated after sonar guided aspiration. The normal budding of thyroid acini were photographed to be taken as a control for pathological findings (Figure 1). Cases with cytohistological disparity were selected and reevaluated for detection of the possible cause. Patients with benign diagnoses were followed-up with repeated clinico-radiologic assessment. Nodules showing significant growth or clinical features of progression (hoarseness of voice, pressure symptoms) underwent a repeat of FNAC. The positive and negative FNAC results for diagnosis of malignancy in relation to the histopathology of cell-blocks were determined. Also, the sensitivity, specificity, diagnostic accuracy, positive predictive value (PPV) and negative predictive value (NPV) were calculated [13].

\section{Results}

All patients were of Egyptian nationality. They were residents of Zagazig city and the surrounding areas. Age of cases in this study ranged from 15 to 65 years, with a median age of 40 years. Cases of papillary carcinoma were in twenties, from 21-27 year old, while anaplastic carcinoma was found at the age of 65 years. No definite age for follicular adenoma or colloid goiter was recognized. Sex distribution of case numbers was 35 and 50 for males and females respectively, with ratio of 7:10. However, sex distribution of malignancy was insignificant.

Table 1 summarizes the findings of FNAC smears while results of histopathological diagnoses are shown in table 2 . There were 52 cases $(61 \%)$ diagnosed by FNAC as colloid goiters. These cases revealed true negative results as indicated with the histopathological examination of cell blocks (Table $2 \&$ Figures 2,3). Cases which were diagnosed in FNAC as Hashimoto`s thyroiditis, branchial cleft cyst and thyrogolssal cysts were of the same diagnosis in histopathological picture i.e. true negative results (Figures 4-9). Cases of follicular neoplasm without atypia revealed follicular adenoma in histopathology (Figure 10). Cases diagnosed as follicular neoplasm with atypia were diagnosed histopathologically as papillary carcinoma of follicular variant (Figures 11, 12). Cases which were diagnosed as suspicious of malignancy ( 2 cases); one of them revealed colloid goiter and the other showed follicular carcinoma (Figures 13,14). Cases of papillary carcinoma (10 cases) and anaplastic carcinoma (one case) appeared of the same diagnosis in histopathology (Figures 15-18). FNAC results showed that sensitivity was $91.6 \%$, specificity was $97.2 \%$, positive predictive value (PPV) was $84.6 \%$, negative predictive value (NPV) was $98,5 \%$, false positive rate (FPR) was $66.6 \%$, false negative rate was $33.3 \%$. Then, total accuracy was $95.2 \%$.

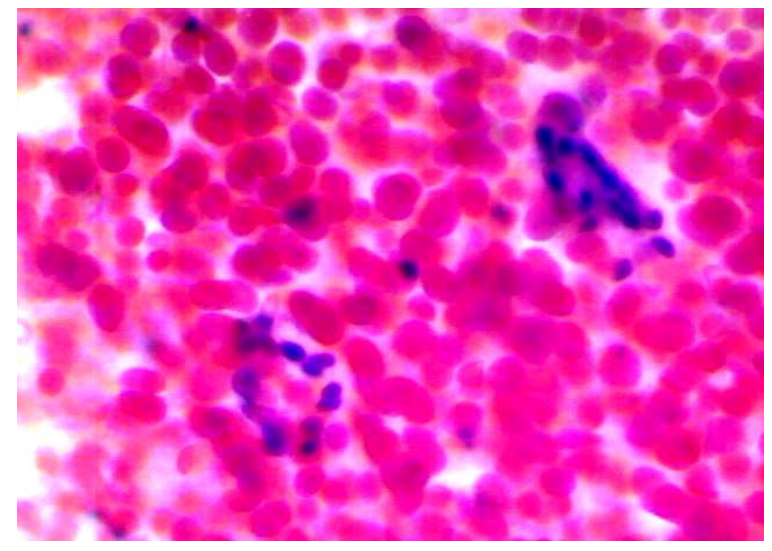

Figure 1. FNAC smear showing normal budding of thyroid acini, in a female with 16 years old. (Hx \& E, X 400)

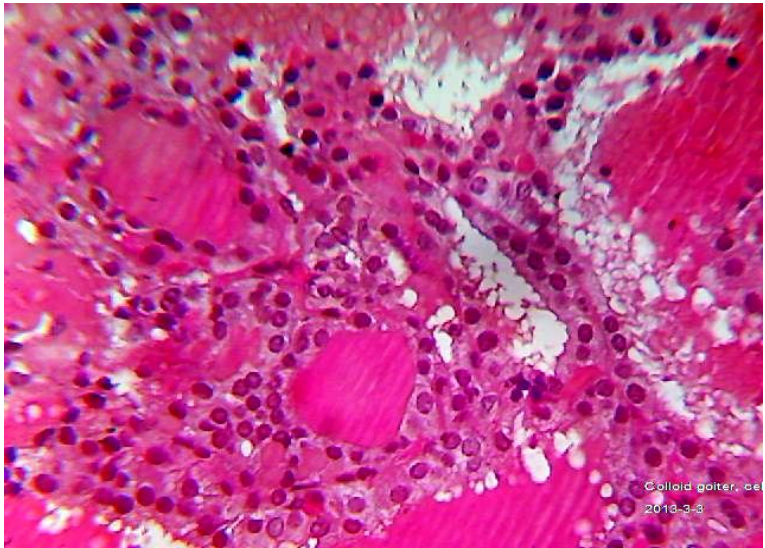

Figure 2. Cell-block froma case of colloid goiter. There are thyroid acini, filled with colloid, and lined by follicular cells; monotonous with homogenous-stained nuclei. (Hx \& E, X400)

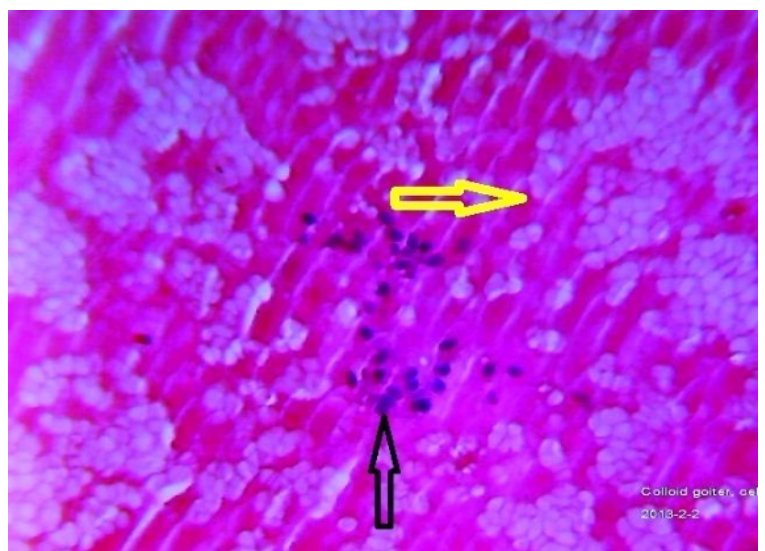

Figure 3. A case of colloid cyst, cell-block. Few follicular cells (the black arrow), spindle-shaped in a background of colloid material and numerous degenerated cells (the yellow arrow) are shown. (Hx \& E, X400) 


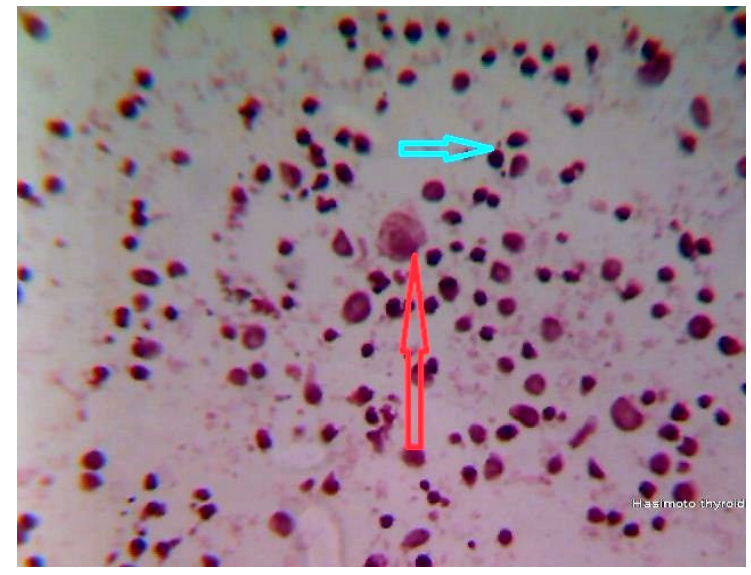

Figure 4. A case of Hashimoto's thyroiditis, smear. There are few follicular cells; rounded with central nulcei, vacuolated cytoplasm ( a degree of degenerative changes) (the red arrow), in a background of high lymphocytic infiltration (the blue arrow). (Hx \& E, X400)



Figure 5. The same case of Hashimoto thyroiditis, cell-block. The lymphocytic infiltrates appear as a lymphoid follicle, and plasma cell could be seen 'the land mark for Hashimoto's thyroiditis' (the red arrow). (Hx \& E, $\mathrm{X} 400)$

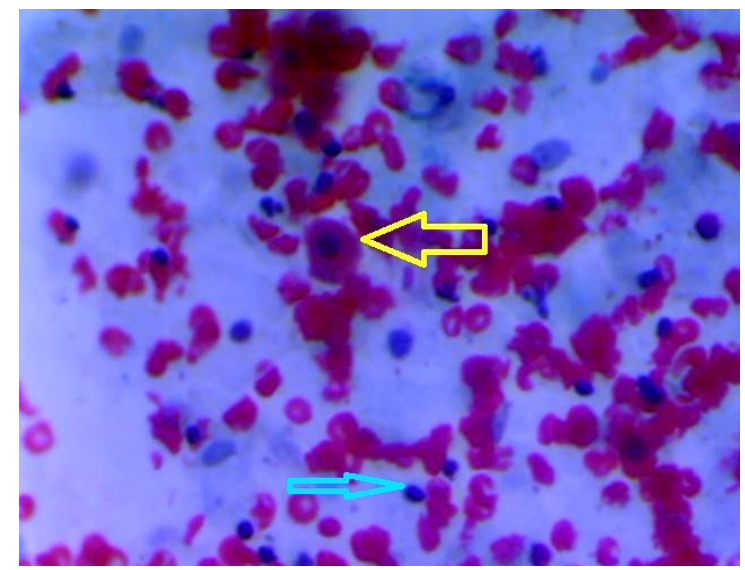

Figure 6. Branchial cleft cyst, smear. Epithelial cells (yellow arrow), lymphocytes (blue arrow) are shown. (Pap, X 400)



Figure 7. A case of branchial cleft cyst, cell-block. Few degenerated epithelial cells (the red arrows) in a background of lymphocytes (the blue arrow) are shown. (Hx \& E, X400)

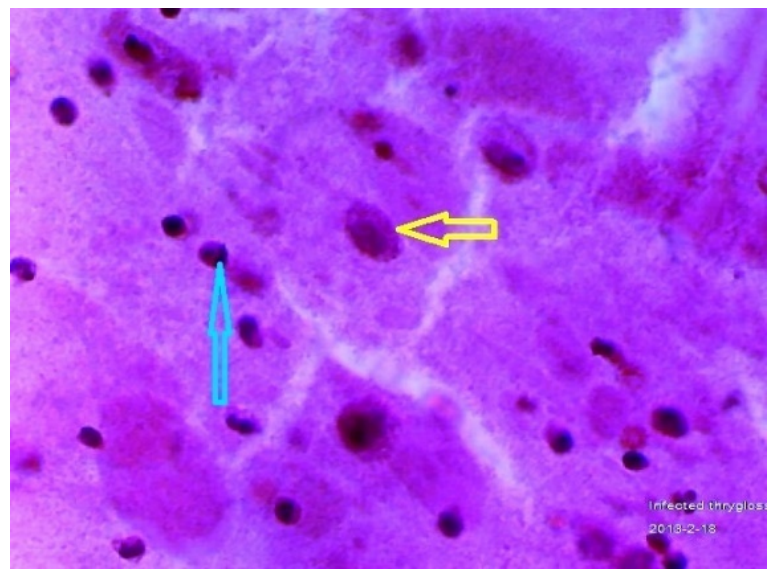

Figure 8. A case of infected thyroglossal cyst, cell-block. Follicular thyroid cells (the yellow arrow) are apparent, in addition to P.N.L`s (the blue arrow) in a background of colloid material. ( $\mathrm{Hx} \& \mathrm{E}, \mathrm{X} 400)$.

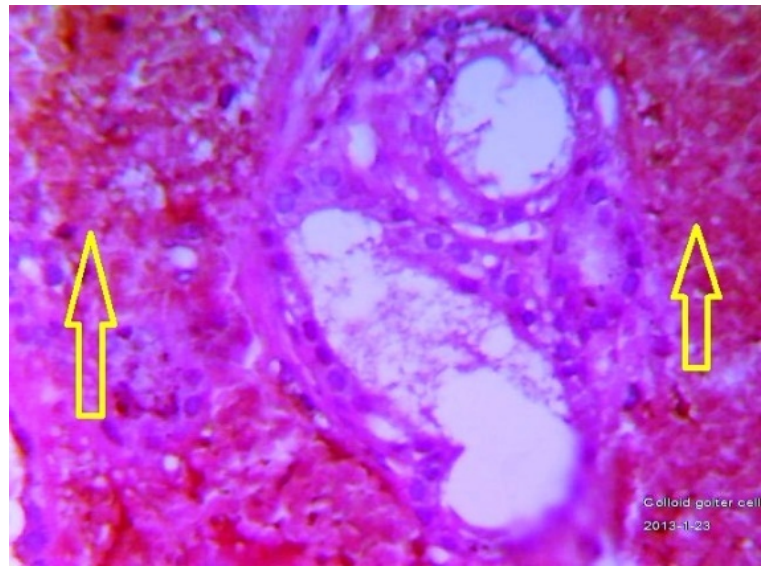

Figure 9. A case of follicular neoplasm, cell-block showing no atypia, but with hemorrhagic changes (yellow arrows). (Hx \& E, X400) 


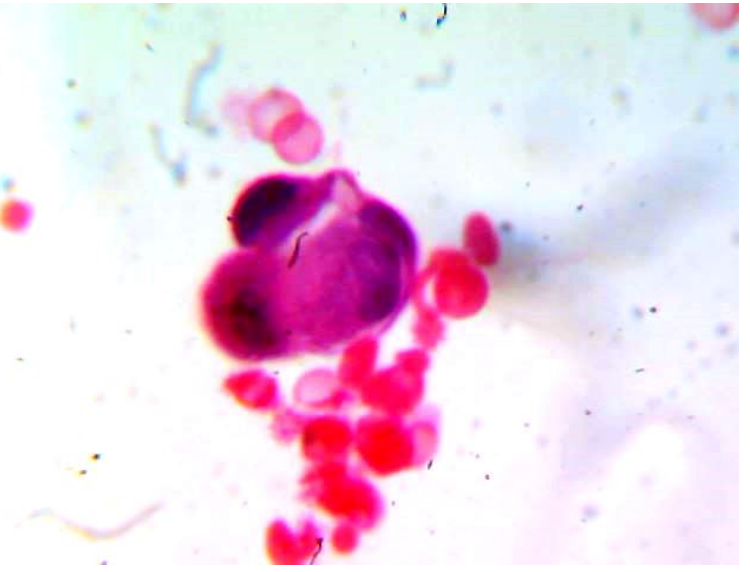

Figure 10. A case of follicular neoplasm with cytological atypia, smear. There is a cluster of follicular cells forming a papilla. The cells are hyperchromatic, pleomorphic, however, other nuclear features of papillary carcinoma are not apparent. (Hx \& E, X1000)

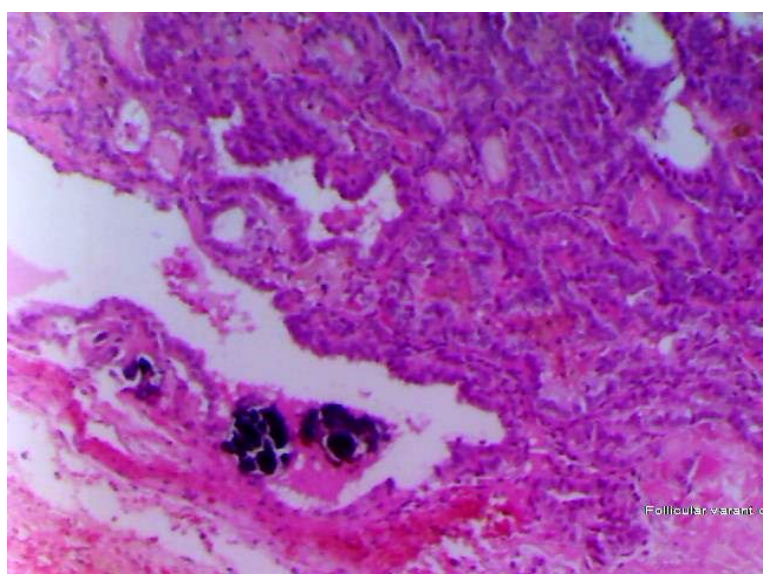

Figure 11. Histopathological picture of the previous case, showing follicular variant of papillary carcinoma. (Hx \& E, X400)

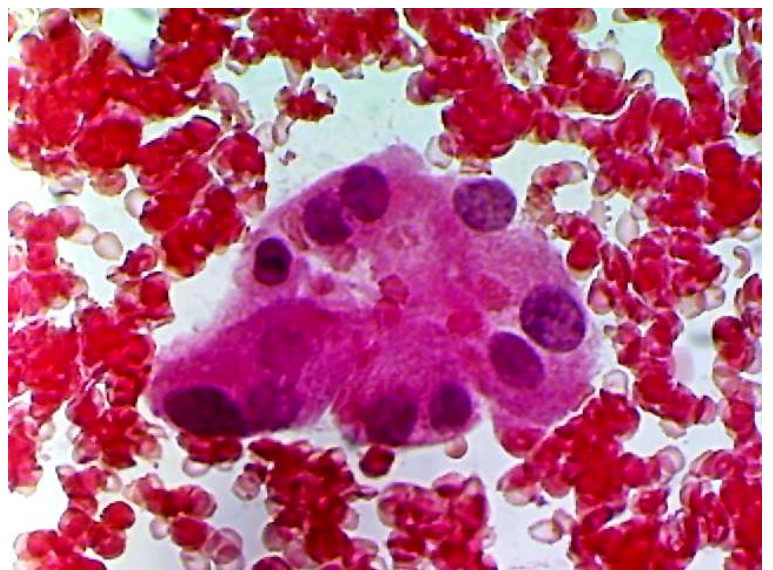

Figure 12. A case of follicular neoplasm with atypia, smear. The follicular cells form a papilla. The cells are hyperchromatic, pleomorphic, but the nuclear changes are not apparent. (Hx \& E, X400)



Figure 13. Cell-block of the previous case; showing follicular carcinoma histopathologically. There is pleomorphism, hyperchromatism, prominent nucleoli (yellow arrows). (Hx \& E, X400)

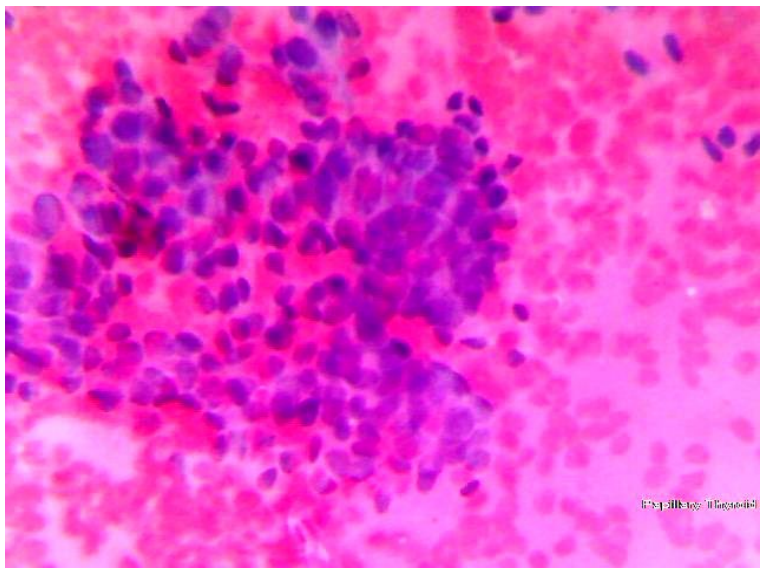

Figure 14. A case of papillary thyroid carcinoma, smear. There's hyperchromatism, pleomorphism, but the other nuclear features of papillary carcinoma are not apparent. (Hx \& E, X400)



Figure 15. A case of papillary thyroid carcinoma, cell-block. The papillary configuration is apparent, with pleomorphism and hyperchromatism of the cell lining. (Hx \& E, X400) 


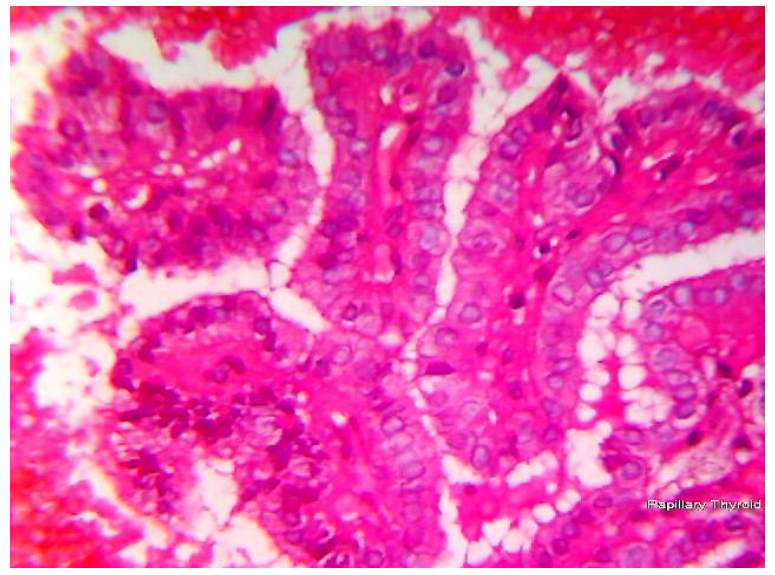

Figure 16. A case papillary thyroid carcinoma, cell-block with papillary configuration, in addition to the nuclear features. (Hx \& E, X400)

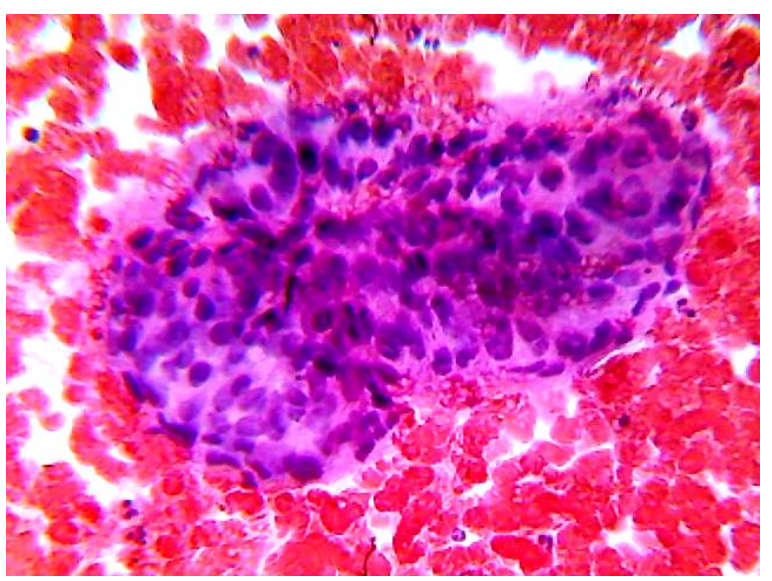

Figure 17. A case of cancer thyroid of undefined category, smear, overlapping, hyperchromatism and pleomorphism. (Hx \& E, X400)

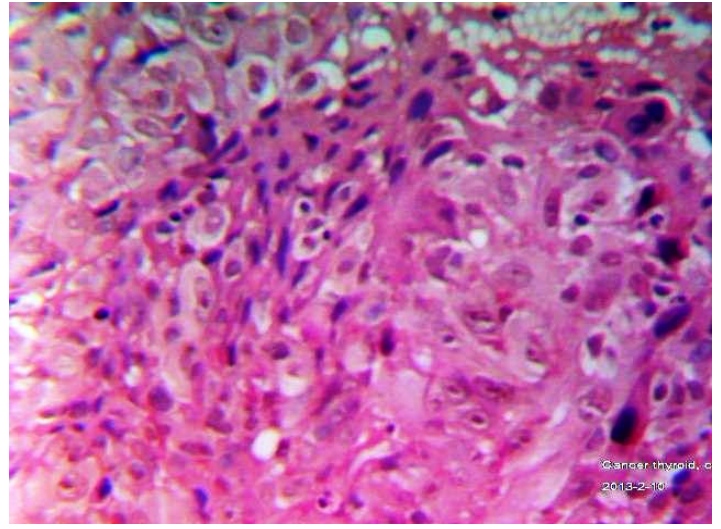

Figure 18. The same case of cancer thyroid of undefined category, cell-block. There is hyperchromatism, pleomorphism, pale esinophilic cytoplasm, mitotic figures. (Hx \& E, X400)

Table 1. Distribution of cases according to FNAC diagnosis

\begin{tabular}{|l|l|l|}
\hline Cytologic diagnosis & Number & Percentage \\
\hline Insufficient & 5 & $5.8 \%$ \\
\hline Colloid goiter & 52 & $61 \%$ \\
\hline Hashimoto thyroiditis & 5 & $5.8 \%$ \\
\hline Branchial cleft cyst & 2 & $2.3 \%$ \\
\hline Thyroglossal cyst & 1 & $1.1 \%$ \\
\hline $\begin{array}{l}\text { Follicular neoplasm } \\
\text { without atypia }\end{array}$ & 5 & $5.8 \%$ \\
\hline $\begin{array}{l}\text { Follicular neoplasm with } \\
\text { atypia }\end{array}$ & 2 & $2.3 \%$ \\
\hline Suspicious of malignancy & 2 & $2.3 \%$ \\
\hline $\begin{array}{l}\text { Papillary thyroid } \\
\text { carcinoma }\end{array}$ & 10 & $11.7 \%$ \\
\hline $\begin{array}{l}\text { Cancer thyroid of } \\
\text { undefined category }\end{array}$ & 1 & $1.1 \%$ \\
\hline Total & 85 & $100 \%$ \\
\hline
\end{tabular}

Table 2. Relation of cytological diagnosis to histopathological diagnosis

\begin{tabular}{|l|l|l|l|l|}
\hline Cytologic diagnosis & No. & Histopathological diagnosis & No & Remarks \\
\hline Colloid goiter & 52 & $\begin{array}{l}\text { Colloid goiter } \\
\text { fetal adenom } \\
\text { follicular adenoma } \\
\text { Colloid cyst }\end{array}$ & $\begin{array}{l}40 \\
2 \\
5\end{array}$ & $\begin{array}{l}\text { True negative } \\
\text { True negative } \\
\text { True negative } \\
\text { True negative }\end{array}$ \\
\hline Hasimoto thyroiditis & 5 & Hashimoto thyroiditis & 5 & True negative \\
\hline Branchial cleft cyst & 2 & Branchial cleft cyst & 2 & True negative \\
\hline Thyroglossal cyst & 1 & Thyroglossal cyst & 1 & True negative \\
\hline Follicular neoplasm without atypia & 5 & Follicular adenoma & 5 & True negative \\
\hline Follicular neoplasm with atypia & 2 & Papillary carcinoma , follicular variant & 2 & False negative \\
\hline Suspicious of malignancy & 2 & $\begin{array}{l}\text { Colloid goiter } \\
\text { follicular carcinoma }\end{array}$ & 1 & 1 \\
\hline Papillary thyroid carcinoma & 10 & Papillary carcinoma & 10 & False positive \\
\hline Cancer thyroid of undefined category positive
\end{tabular}




\section{Discussion}

Thyroid gland is a highly vascular endocrine gland. It resembles a butterfly in shape, formed of two lobes connected by an isthmus [14]. It is composed of follicles and parafollicular (or C-) cells. The follicular cells which convert iodine into thyroxine and triiodothyronine are derived from the foregut endoderm while the parafollicular cells secreting calcitonin originate from the ultimobranchial body of the fourth pharyngeal pouch [15]. Thyroid tumors arise from these very different kinds of cells or from nonepithelial stromal elements [16]. The gland is unusual in having more forms of cancer than other monoepithelial tissues or organs such as breast or prostate. Classification into papillary, follicular, medullary and anaplastic types is generally accepted [17]. In this study, papillary carcinoma was detected in the twenties, while anaplastic carcinoma was found at age of 65 years. This finding is similar to the conclusion of previous literature stating that the risk of malignancy is increased for thyroid swelling at extremes of age [18].

Although thyroid cancer is the most common type of endocrine malignancy, it carries a favorable prognosis with the early and appropriate management [19]. It is therefore important to have a structured diagnostic method to ascertain the risk of malignancy in thyroid lesions. This study agreed with the importance of FNAC in clinical management of thyroid nodules reported in other literature [20]. The overall accuracy of FNAC for detection of neoplasm in the current study was $95.2 \%$, whereas it varied from $69 \%$ to $96.2 \%$ in other studies $[13,21]$. Despite the proved clinical importance of thyroid FNAC, it still has limitations related not only to inadequate sampling but also, most importantly, to its inability to define malignant follicular lesions in the absence of nuclear features of papillary carcinoma [22]. We introduced cell-block study in order to improve the accuracy and the interpretation. Other studies were performed on cell block of thyroid lesions; however, the contribution was minimal because of the low cellularity [23]. In regards to the adequacy of the samplings, we found some cases which were negative in the smear and predictive in the cell-block. This finding may be attributed to inefficient smearing. In this group, the aspirates were consisting of cyst fluid, however cell-block may resolve this problem; as the fluid was centrifuged, then cell-block was prepared. FNAC results were then compared with the definitive histological diagnosis. The difficulty in distinguishing benign from malignant cases in the FNAC, explain our findings of two cases diagnosed cytologically as suspicious of malignancy and revealed in histopathology as colloid goiter in one case and follicular carcinoma the other. The indeterminate diagnosis of follicular neoplasm includes a number of heterogeneous thyroid lesions such as cellular adenomatoid nodule, follicular adenoma, and follicular carcinoma [24]. This agreed with our findings in the cases diagnosed as follicular neoplasm without atypia and revealed as follicular adenoma. Additionally, the interpretation of follicular variant of papillary carcinoma (FVPC) in cytology may be difficult when prominent classic nuclear features of papillary thyroid carcinoma are absent. In our study, we found 2 cases diagnosed as follicular neoplasm with atypia and showed papillary carcinoma of follicular variant at histopathological investigation. In such cases, a preoperative diagnosis of "follicular lesion suggestive of papillary carcinoma" results in conservative surgical assessment until a definitive diagnosis can determine the appropriate line of treatment [25]. We consider the diagnosis of follicular neoplasm with atypia to be more descriptive. Another limitation of FNAC is the presence of false negative and positive results particularly with small tumors and when there is associated degenerative or inflammatory change in adjacent thyroid tissue, and needle do not go through the particular lesion. We found one case (false negative and two cases false positive. In addition, there is a group of lesions in which overlap benign and malignant features might be found [26]. Indeed, we found 7 cases which were diagnosed cytologically as colloid goiter by smear and showed fetal adenoma ( 2 cases) and follicular adenoma (5 cases) in the histopathological diagnosis. Hall et.al, [27] agreed with this finding and accounted that the distinction between a cellular colloid goiter and a follicular neoplasm may be impossible. Cystic nodules were detected in 5 cases $(5.8 \%)$ of our study which were previously diagnosed in cytology as colloid goiter, representing $10-25 \%$ of all thyroid nodules in other literature [28]. This represents additional diagnostic challenges. Cystic degeneration may be observed in both benign and malignant thyroid nodules. The malignancy rate within cystic thyroid nodules is $10 \%$ [29]. However, conventional FNAC for cystic thyroid nodules has a high rate of non-diagnostic and false negative results [30]. Cell-block may resolve this problem, as a large amount of the fluid was aspirated and centrifuged. Then, processing of the sediment as a cell-block was done. The few follicular cells that may appear within a large number of degenerated cells might easily rule out malignancy, and negate the misdiagnosis of inadequate sample, or false results. The few thin-walled cysts will collapse completely with needle evacuation [29, 30]. We recorded one such case that was followed-up for more than 2 years without harm. Most cysts, however, have a partially solid component, and these cysts should be aspirated for residual tumor. Initially, the cystic fluid, if not excessively viscous, should all be aspirated and sent for cytopathologic evaluation. Ultrasound-guided FNAC can then be performed to sample the suspicious solid component. Ultrasound (US) investigation permits direct sampling of the wall and/or the solid portion of the cystic thyroid nodule, thereby increasing the possibility of a representative sample $[30,31]$. However, due to difficulties both in obtaining adequate tissue sampling, and in accurately detecting enlargement of the solid portions of these nodules, surgery should be considered for persistent and recurrent complex cystic nodules for both diagnostic and therapeutic reasons [29]. Surgery is indicated especially for cystic thyroid nodules $>4 \mathrm{~cm}$, since the risk of malignancy is higher in large cystic lesions [31]. For accurate risk 
estimation in cystic thyroid nodules, other characteristics should also be taken into account, such as sex and findings of local invasion in imaging [31]. Experience is also required from the histopathologist who interprets the specimen. Inexperienced histopathologists may report a very high proportion of follicular lesions or suspicious biopsy specimens, perhaps from lack of confidence in interpreting those nodules that are benign. The endocrinologist should closely cooperate with the pathologist, especially on difficult cases [32]. The investigator should adhere to appropriate criteria for specimen adequacy ( $>6-8$ clusters smeared on slides) and he/she should report the cellularity of the specimen and whether it is sufficient for the diagnosis. Such teamwork will avoid the problem of a report such as "no malignant cells seen" in a specimen that is hypocellular or even acellular, resulting in a false conclusion of a benign FNA biopsy specimen [32]. With the exception of calcitonin immunostaining for medullary carcinoma, there are no reliable immunohistologic or molecular tests for distinguishing between benign and malignant nodules based on microscopic findings [33]. In regards to Hashimoto thyroiditis, cell-block was useful for finding the few degenerated follicular cells, due to good fixation, and also in detection of plasma cells which was pathognomonic for diagnosis of Hashimoto thyroiditis. In cases of branchial cleft cysts and thyroglossal cysts, cell-block was also very useful, as the epithelial cells and follicular cells become more clear, also due to good fixation of the cell-block. Moreover, cell-block was very helpful in the diagnosis of papillary thyroid carcinoma and the carcinoma of undefined category; as the papillary configuration and nuclear features were more obvious.

Regarding to what is called non-aspirated technique, the cellular material is more concentrated, less traumatized and less obscured by blood or distorted within blood clots in the non-aspiration smears [34-36]. Cell-block may give a better result than this technique because of good fixation of the specimens as well as good interrelation between the cells. This also reduces the range of inadequacy. The inadequacy of smears was $15 \%$ but cell block reduced it to $(5.8 . \%)$. In this study, we don`t gush the blood by the syringe, this gives less trauma of the follicular cells. Also, cell-block gives more good interrelation of the cells together, forming follicles or papillae. Also, the nuclear features become more clear and obvious.

\section{Conclusions}

We advise to perform cell-block for each cases of FNAC, for all thyroid lesions, if possible, in order for; less pitfalls, less false negative, less false positive cases and more definite diagnosis. This helps to avoid unnecessary surgery in cases of misdiagnosis.

\section{Acknowledgements}

Great thanks to Mr. Ahmed E M Faisal, technician of histopathology for preparation of slides and cell-blocks in this study.

\section{REFERENCES}

[1] A. K. Niazi, S .Kalra, A. Irfan, et al. Thyroidology over the ages. Indian J Endocrinol Metab, Vol. 15, No. 2, S121-S126, 2011.

[2] J. I. Hamburger. Thyroid nodules and thyroid cancer. Clinical exercises in internal medicine: thyroid diseases, W.B. Saunders, Philadelphia, 199-226, 1978.

[3] T. W. Furlanetto , S. Peccin, M. A. de O Schneider, et al. Prevalence of thyroid nodules in 40 years-old or old women. Rev Assoc Med Bras, Vol. 46, No. 4,331-334, 2000.

[4] J. D. Mortensen, L. B. Woolner, W. A. Bennett. Gross and microscopic findings in clinically normal thyroid glands. Journal of clinical endocrinology and metabolism, Vol. 15, 1270-1280, 1955.

[5] M. J. Welker, D. Orlov. Thyroid nodules. Am Fam Physician, Vol. 67, No.3,559-567, 2003.

[6] T. Acar, S. S. Ozbek, S. Acar. Incidentally discovered thyroid nodules: frequency in an adult population during Doppler ultrasonographic evaluation of cervical vessels. Endocrine, Vol. 8, 2013.

[7] S. A. Roman. Endocrine tumors. Evaluation of thyroid nodule. Curr Opin Oncol, Vol.15, 66-70, 2003.

[8] R. M. Walsh, J. C. Watkinson, J. Franklyn. The management of the solitary thyroid nodule: a review. Clin Otolaryngol Allied Sci, Vol. 24:388-397, 1999.

[9] M. Amrikachi, I. Ramzy, S. Rubenfeld, T. M. Wheeler. Accuracy of fine needle aspiration of thyroid: a review of 6226 cases and correlation with surgical and clinical outcome. Arch Pathol Lab Med, 125:484-488, 2001.

[10] H. Galera-Davidson. Diagnostic problems in thyroid fine needle aspirations. Diagn Cytopathol, Vol. 17, 422-428, 1997.

[11] T. J. Smit, H Safali, E. A. Foster, R. B. Reinhold. Accuracy and cost effectiveness of fine needle aspiration biopsy. Am J Surg, Vol. 149, 540-555, 1985.

[12] S. R. Orell. In: Orell SR, Sterrett GF, Walters MN, Whitakar $\mathrm{D}$, editors. Manual and atlas of fine needle aspiration cytology. New Delhi: Churchill-Livingstone, 125-164, 2005.

[13] P. K. Bagga, N. C. Mahajan. Fine needle aspiration cytology of thyroid swellings: How useful and accurate is it?, Indian J Cancer, Vol. 47, 437-442, 2010.

[14] A. Waugh, A. Grant. Anatomy and Physiology in Health and Illness. 9th ed., Churchill Livingstone, 219-221, 2004.

[15] T. W. Sadler. Longman's Medical Embryology. 12th ed., Lippincott Williams \& Wilkins, 262-275. 2012.

[16] C. D. Scopa. Histopathology of thyroid tumors: An overview. Hormones, Vol. 3, No. 2, 100-110, 2004. 
[17] W. W. Park. Lesions of the Thyroid Gland. The Histology of Borderline Cancer, Springer-Verlag, 41-65, 1980.

[18] C. Y. Eng, M. S. Quraishi, P. J. Bradley. Management of thyroid nodules in adult patients. Head \& Neck Oncology. 2010 Online available from http://link.springer.com/article/10.1186/1758-3284-2-11/fullt ext.html

[19] R. V. Datta, N. J. Petrelli, J. Ramzy. Evaluation and management of incidentally discovered thyroid nodules. Surgical oncology, Vol. 15:33-42, 2006.

[20] P. Caruso, E. L. Muzzaferri. Fine needle aspiration biopsy in the management of thyroid nodules. Endocrinology, Vol. $1: 194-202,1991$.

[21] E. L. Cusick, C. A. MacIntoch, Z. H. Krukowski, et al. Management of isolated thyroid swelling: a prospective six year study of fine needle aspiration cytology in diagnosis. British Medical Journal, Vol. 301, No. 6747, 318-321, 1990.

[22] S. Fischer, S. L. Asa. Application of immunohistochemistry to thyroid neoplasms. Archives of Pathology \& Laboratory Medicine, Vol. 132, No. 3, 2008. Online available from http://www.biomedsearch.com/article/Application-immunoh istochemistry-to-thyroid-neoplasms/230416900.html

[23] N .Sanchez, S. M. Selvaggi. Utility of cell blocks in the diagnosis of thyroid aspirates. Diagn Cytopathol. Vol.34, No.2, 89-92, 2006

[24] E. Saggiorato, P. R. De, M. Volante. Characterization of thyroid 'follicular neoplasms' in fine-needle aspiration cytological specimens using a panel of immunohistochemical markers: a proposal for clinical application. EndocrRelat Cancer, Vol. 12, 305-317, 2005.

[25] E. D. Rossi, M. Raffaelli, C. Minimo, et al. Immunocytochemical evaluation of thyroid neoplasms on thin-layer smears from fine-needle aspiration biopsies. Cancer 2005;105:87-95.

[26] D. Giuffrida, H. Gharib. Controversies in the management of cold, hot, and occult thyroid nodules. Am J Med, Vol. 99, 642-650, 1995

[27] T. L. Hall, L. J. Layfield, A. Philippe, et al. Source of diagnostic error in the fine needle aspiration of the thyroid. Cancer; Vol. 63, 718-725, 1989.

[28] H. B. Bursh. Evaluation and management of the solid thyroid nodule. Surgical Clinics of North America, Vol. 24, 663-710, 1995.

[29] K. U. Choi, J. Y. Kim, Y. Park do, et al. Recommendations for the management of cystic thyroid nodules. Australian and New Zealand Journal of Surgery, Vol. 75, 537-541, 2005.

[30] M. D. Smith, J. W. Serpell, J. L. Morgan, et al. Fine needle aspiration in the management of benign thyroid cysts. Australian and New Zealand Journal of Surgery. Vol. 73, 477-479, 2003

[31] R. Bellantone, C. P. Lombardi, M. Raffaelli et al. Management of cystic or predominantly cystic thyroid nodules: the role of ultrasound-guided fine-needle aspiration biopsy. Thyroid, Vol. 14, 43-47, 2004.

[32] S. Feld. AACE clinical practice guidelines for the diagnosis and management of thyroid nodules. Endocrine Practice, Vol.
2, 78-84, 1996.

[33] L. Hegedus, S. J. Bonnema, F. N. Bennedbaek. Management of simple nodular goiter: current status and future perspectives. Endocrine Reviews, Vol. 24, 102-132, 2003.

[34] P. Dey, Shashriekha, R. Ray. Fine needle sampling without suction in intra abdominal lesions: Comparison with fine needle aspiration. Acta Cytol, Vol. 38, 495-496, 1994.

[35] D. Fagelman, Q. Chess. Non-aspiration needle cytology of liver; A new technique for obtaining diagnostic samples. AJR Am J Roentgenol, Vol. 155, 1217-1219, 1990.

[36] X. H. Yue, S. F. Zheng. Cytological diagnosis by transthoracic needle sampling without aspiration. Acta Cytol, Vol. 33, 805-808, 1989 